\title{
AS ESCOLAS ELEMENTARES PAULISTAS E SEUS ALUNOS ESTRANGEIROS NA PASSAGEM DO SÉCULO XIX PARA O XX.
}

Eliane Mimesse Prado ${ }^{1}$

\section{RESUMO:}

Efetuou-se um levantamento das escolas elementares no estado de São Paulo, nos anos finais do século XIX e início do XX. O grande número de crianças estrangeiras e de filhas de estrangeiros em idade escolar, provenientes da península itálica, suscitou discussões entre os inspetores de ensino e posteriores alterações na organização e fiscalização dessas escolas. Muitas crianças nascidas no Brasil frequentavam as escolas privadas subsidiadas pelo governo italiano e eram escolarizadas segundo os preceitos daquele governo. Essas escolas subsidiadas tinham como sede, na maioria das vezes, as associações de socorro mútuo. O governo paulista criava escolas elementares nos núcleos coloniais e nas sedes dos municípios. Mas, nem sempre essas escolas eram providas com professores, edifícios ou materiais para o ensino, principalmente as mais afastadas dos centros urbanos. Normalmente, os próprios moradores supriam as escolas com os objetos que necessitavam. As fontes dessa pesquisa encontram-se no acervo do Arquivo Público do Estado de São Paulo. Os autores consultados foram: Di Lorenzo (2002), Silveira (2007), Mimesse (2010), entre outros. Conclui-se que muitas crianças estrangeiras e filhas de estrangeiros frequentaram as escolas elementares paulistas.

Palavras-chave: escolas elementares; imigrantes peninsulares; história da educação.

\section{ELEMENTARY SCHOOLS IN THE STATE OF SÃO PAULO AND THEIR FOREIGN STUDENTS AT THE TURN OF THE $19^{\text {TH }}$ TO THE $20^{\text {TH }}$ CENTURY.}

\begin{abstract}
:
A survey was conducted on elementary schools in the state of São Paulo in the final years of the $19^{\text {th }}$ century and beginning of the $20^{\text {th }}$ century. The large number of foreign children and foreigners' daughters at school age, coming from the Italian Peninsula, sparked discussions among school inspectors, and caused subsequent alterations in the organization and inspection of those schools. Many children born in Brazil went to private schools that were subsidized by the Italian government and were educated according to what that government dictated. In most cases, the mutual help associations were the headquarters of those subsidized schools. The government of São Paulo created elementary schools in the colonial settlements and in the cities. Those schools, were not always provided with teachers, facilities or teaching materials, especially those further away from the city center. Locals were usually the ones who provided the schools with objects they needed. The sources for this research can be found in the collection of the Public Archive of the State of São Paulo. The authors consulted are: Di Lorenzo (2002), Silveira (2007), Mimesse (2010). We concluded that many foreign children and foreigners' daughters attended the state of São Paulo's elementary schools.
\end{abstract}

Keywords: elementary schools; peninsular immigrants; history of education. 


\section{Introdução}

Este estudo foca, de modo ainda sucinto, a criação e organização das escolas de Primeiras Letras existentes em núcleos coloniais e centros urbanos no estado de São Paulo, que foram frequentadas, por alunos estrangeiros. Esses alunos eram filhos de imigrantes, principalmente peninsulares, nascidos neste ou no reino italiano recémunificado.

O período instituído para a pesquisa inicia-se no ano de 1877, quando da chegada de muitos peninsulares no estado de São Paulo, e da consequente criação de novos núcleos coloniais destinados para sua moradia e, das concludentes e respectivas escolas elementares instaladas nessas localidades. O ano final de 1910 foi escolhido por ser a data em que ainda se encontravam núcleos no estado, com concentração de população peninsular. Apesar da redução da entrada desses imigrantes no Brasil, como consequência a um decreto do governo italiano que proibia a imigração subsidiada para as terras brasileiras.

As escolas de Primeiras Letras foram criadas por todo o estado e nos núcleos coloniais paulistas pelo governo, mas na maioria das vezes, não eram supridas com materiais, móveis ou mesmo um edifício. O governo nomeava os professores, que acabavam por improvisar o local para ministrarem suas aulas. Muitas vezes os próprios colonos proviam as escolas com materiais e cediam o espaço físico para sua instalação.

Em alguns casos, as escolas, tinham edifício, materiais e professores vinculados as sociedades de ajuda mútua, que cobravam mensalidades dos alunos e recebiam subsídios do governo italiano para sua manutenção. As escolas localizadas nas áreas urbanas contavam, na maioria das vezes, com o subsídio do governo italiano, em espécie e em materiais para as aulas. Essas mensalidades eram de valor baixo e não eram cobradas das famílias dos alunos que comprovassem a impossibilidade do pagamento.

\section{As precárias escolas de Primeiras Letras.}

A denominação de escolas de Primeiras Letras surgiu em decorrência dos conteúdos básicos que eram ensinados, rudimentos da leitura, escrita e do cálculo. Todas as escolas de ensino elementar eram consequentemente de Primeiras Letras. Essas escolas foram denominadas legalmente pelo governo como: isoladas, masculinas, femininas, mistas, reunidas ou grupos escolares. Essas modalidades de escolas atendiam as crianças em idade escolar, entre os cinco e os doze anos. Todas eram públicas e compostas da seguinte maneira: Escolas Isoladas segmentadas em femininas, masculinas ou mistas, continham uma única sala de aula, agregavam alunos de idades e níveis de aprendizagens diferentes; Escolas Reunidas uniam algumas escolas isoladas em um mesmo espaço físico, algumas vezes tinham a presença de um diretor e Grupos Escolares que contavam com um professor por sala, um diretor e um servente, as salas de aulas eram organizadas segundo a idade dos alunos, o sexo e o ano escolar no qual estavam, e ainda eram localizados em edifício único. Esses tipos de escolas formavam os alunos no curso primário, que tinha a duração de três anos, como as escolas isoladas e algumas reunidas, ou de quatro anos como os grupos escolares.

As escolas isoladas eram mantidas pelo governo do Estado, as que existiam no estado de São Paulo, nos anos finais do século XIX e iniciais do século XX apresentavam deficiências no seu funcionamento. 
Desde o Império existia a necessidade de criação de escolas elementares nos núcleos coloniais, com a Lei Estadual n. 28, de 29 de março de 1884, previa-se a criação de uma cadeira mista de instrução primária em cada núcleo colonial, o que foi reafirmado com o Regulamento para o Serviço de Imigração do Estado de São Paulo de 30 de agosto de 1887. De acordo com Cunha (2006) a Lei Estadual n. 1.458 de 10 de abril de 1907 garantiu a instrução aos filhos de colonos em escolas públicas, com intuito de educá-los. Entretanto, não se pode afirmar que essas escolas foram criadas e providas.

Podem-se listar os problemas por elas encontrados no seu desenvolvimento, quanto ao espaço físico, aos materiais didáticos, a formação dos professores e a diversidade de métodos de ensino aplicados. Muitas foram as críticas endereçadas a essas escolas.

Normalmente, o espaço físico destinado à escola elementar de um modo geral era indevido, por ocupar um cômodo qualquer ou uma das salas de uma residência de família, como a do próprio professor. Um dos inspetores escolares estaduais descreveu uma solução para a situação:

[...] a primeira providencia que reclama a escola isolada e se impõe, exigindo prompta execução, é a construcção de casas escolares, de accordo com os preceitos da hygienepedagogica. [...] O onus que pesa sobre os modestos vencimentos do professor isolado com o estipendio dos alugueis do aposento escolar, o obriga naturalmente a reduzir ao minimo tal despeza, procurando pequenas salas, imprestaveis sob todos os aspectos, com flagrante sacrificio dos preceitos hygienicos e menospreso pelas regras pedagogicas. (SÃO PAULO, 1910, p. 50)

Outra apreciação que pairava nos debates sobre a precariedade das escolas isoladas era quanto à inexistência de mobiliário escolar, usavam-se bancos, caixotes de madeira, mesas improvisadas e cadeiras dos mais diversos tipos, muitas vezes cedidos pelos pais dos alunos. Fato este explicitado por Mimesse (2010) quando da pesquisa com escolas isoladas femininas e masculinas, criadas no núcleo colonial vêneto de São Caetano, no final do século XIX nos arredores da Capital paulista, local da atual cidade de São Caetano do Sul.

No ano de 1901, no antigo núcleo de Cascalho, na atual cidade de Cordeirópolis, como foi relatado por Silveira (2007) registrou-se na documentação a existência de um ofício do professor da $1^{\mathrm{a}}$ cadeira pública municipal, queixando-se da distância do centro urbano e do preço do aluguel. Identificaram-se nos documentos vários tipos de reclamações, que iam além dos materiais e dos móveis escolares, porque os professores deveriam também, pagar o aluguel dos edifícios em que a escola funcionaria.

As discussões sobre a precariedade das escolas isoladas e os problemas na aprendizagem dos alunos, perpassavam os debates dos inspetores escolares desde os anos finais do século XIX. Eram muitas as falhas que foram constatadas, mas poucas delas foram sanadas. Um inspetor de ensino registrou em seu texto considerações sobre a instabilidade dos professores das escolas isoladas, porque esses assumiam as cadeiras nessas escolas para iniciarem a carreira mais do que,

[...] cuidar de sua única e especial missão de ensinar e educar. Os paes não mandam os filhos á escola, porque já sabem que, durante o ano lectivo, haverá na localidade dous ou tres professores, no intervallo de cujas nomeações haverá ferias forçadas de tres, quatro ou mais mezes, não se contando as licenças occasionadas pelo desanimo dos professores. (SÃO PAULO, 1910, p. 107) 
Os núcleos coloniais, por meio de seus moradores redigiam abaixo-assinados solicitando ao governo a criação e o provimento de escolas elementares para seus filhos. Quando o governo provincial ou estadual - dependendo da época em que encontravam não atendia a essas solicitações, os próprios colonos organizavam-se e criavam as escolas. $\mathrm{O}$ professor normalmente era alguém da comunidade, com conhecimentos sobre os conteúdos a serem ensinados, lecionava o que sabia, no idioma que dominava.

No núcleo colonial estadual do Quiririm, localizado na atual cidade de Taubaté, existia uma escola masculina, que foi designada e provida pelo governo em 1907. No ano de 1909, verificou-se na documentação que já existiam duas escolas femininas e duas masculinas providas. Conforme Di Lorenzo (2002) no ano de 1894 funcionavam duas escolas mistas privadas, que estudavam a língua e a história italianas. Uma das escolas recebia subsídios do governo italiano e a outra era particular. No núcleo colonial imperial de São Caetano as escolas de Primeiras Letras foram criadas pelo governo em 1883, uma feminina e outra masculina, entretanto, não foram providas com materiais ou edifícios próprios, apenas os professores foram nomeados e assumiram seus cargos.

As escolas elementares eram estabelecidas, a princípio, pelos próprios colonos para o ensino dos rudimentos da leitura, escrita e aritmética. Esses colonos entendiam a necessidade da escolarização para facilitar as relações comerciais entre eles e os brasileiros. O governo brasileiro nem sempre construía edifícios para as escolas ou proporcionava condições básicas para o seu funcionamento. Essa ação do governo brasileiro foi suprida aos poucos pelas escolas elementares privadas subsidiadas pelo governo italiano, que criou escolas desta modalidade em todos os países em que existiam emigrados peninsulares.

Muitas das escolas elementares existentes nos núcleos coloniais funcionaram nas dependências da igreja ou das casas dos moradores, durante vários anos, até que os próprios colonos construíssem um edifício adequado. Como sucedeu em algumas das antigas colônias rurais.

Rotineiramente, após a organização do espaço urbano, com a construção das casas e de uma praça central, os colonos solicitavam ao governo a construção de uma igreja, um cemitério e uma escola. Mas, nem sempre eram atendidos em seus requerimentos. Sendo assim, organizavam-se com as doações de terrenos e materiais para as construções. Conseguiam "as suas custas", os edifícios das escolas, da igreja e o cemitério. Fatos que ocorreram, segundo Mimesse (2010) no núcleo de São Caetano; nos núcleos coloniais Campos Sales, na atual cidade de Cosmópolis e Barão de Jundiaí, na cidade de Jundiaí, como informou Corrêa (2000); e no núcleo provincial de Ribeirão Pires, como referido por Granjo (2004). Silveira (2007, p.105) descreveu situação similar no núcleo provincial de Cascalho, quando os colonos solicitaram ao governo a criação de "um cemitério, de uma capela para o culto católico e de uma escola".

O governo não tinha uma preocupação ampla com essa população recém-chegada ao país, não se apressava na construção de edifícios públicos para os colonos, apenas possibilitava o funcionamento desses estabelecimentos, providenciando, a partir de nomeações, os respectivos funcionários.

As escolas isoladas para ambos os sexos eram criadas pelo governo paulista nos núcleos coloniais, os professores eram nomeados, apesar de não existirem materiais ou locais apropriados para o desenvolvimento de suas aulas. Observou-se que em alguns casos eram criadas escolas mistas, para sanar a lacuna educacional na localidade. Com o aumento da população escolar essas escolas eram desmembradas em femininas e masculinas. Existiam também escolas municipais, em algumas cidades paulistas, 
especificamente em 58 municípios, sendo que 14 deles contavam com mais de 200 alunos matriculados. Conforme o Annuario do Ensino do Estado de São Paulo de 1910, esses municípios eram: Amparo, Batatais, Brotas, Campinas, Espírito Santo do Pinhal, Franca, Jaú, Limeira, Mogi-Mirim, Piracicaba, Rio Claro, Santos, São Carlos e São João da Boa Vista.

A lentidão, nas ações do governo paulista, contribuiu para a expansão das escolas subsidiadas pelo governo italiano e, na criação de escolas elementares nos moldes das que existiam nas localidades de procedência desses imigrantes. Era considerada uma prática, o uso dos espaços comunitários para as aulas, na terra natal.

[...] em cada comunidade, além da escola situada no centro [...] as escolinhas mistas, aceitavam meninos e meninas e nem sempre tinham uma só sede, em alguns casos de fato, o local era provavelmente o mesmo utilizado como templo, ou as lições eram tidas no estábulo para desfrutar do calor dos animais. (PISERI, 2012, p. 186, tradução nossa)

A organização e união dos moradores nos núcleos coloniais possibilitou a improvisação das dependências físicas e dos móveis das escolas. Como o governo paulista não atendia prontamente todas as solicitações para a criação de escolas, os imigrantes organizavam-nas, contando com os subsídios enviados pelo governo italiano.

As escolas elementares sempre foram muito difundidas entre os peninsulares, nas mais remotas regiões. No norte da península, nas localidades próximas as fronteiras montanhosas, existia um amplo quadro composto por escolas elementares, que se tem notícias desde o século XVI. Nas regiões mais ao sul da península têm-se relatos de escolas elementares privadas, e de escolas públicas em meados do século XVIII.

Havia certa preocupação dos párocos em alfabetizarem e catequizarem a população peninsular, concomitante com a das comunidades em abrirem e manterem escolas elementares. Para os religiosos a necessidade de se sustentarem escolas elementares assumia outras finalidades. Principalmente nas regiões limítrofes em que diferentes crenças religiosas, poderiam interferir na opção das pessoas. Nesse sentido, a educação adotava funções mais amplas, indo além da alfabetização.

No estado de São Paulo, na maioria dos núcleos coloniais com predominância de peninsulares, foram criadas irmandades visando a organização religiosa juntamente com o pároco, que normalmente não vivia no núcleo. Identificou-se que as ações dos peninsulares seguiam os mesmos moldes do que ocorria em seus locais de origem. As irmandades passaram a existir após o término da tutela do governo paulista aos núcleos coloniais, elas assumiram as ações de organização da comunidade. As funções dessas irmandades tornaram-se religiosas e administrativas, e tenderam a separarem-se, de modo que passaram a se ocuparem somente das questões religiosas, as administrativas seriam geridas pelas recém-criadas associações, denominadas de Associações de Socorro Mútuo. Nestas associações os participantes pagavam taxas para a manutenção das mesmas, e seriam socorridos caso necessitassem de fundos para resolverem questões de âmbito comercial ou de saúde.

As associações de socorro mútuo foram instituídas na maioria dos antigos núcleos coloniais paulistas, e também criaram escolas elementares que funcionavam em suas sedes. A maior parte dessas escolas eram privadas, com frequência somente masculina e ensinavam os conteúdos em língua italiana. É interessante esclarecer que, nessa época, o 
governo italiano oferecia subsídios para as escolas privadas e para as associações de socorro mútuo.

A partir da criação da Società Nazionale Dante Alighieri all'estero, em 1889 já existia o ideal de "difusão da cultura Pátria, que devia defender uma identidade nacional, entre os italianos emigrantes e principalmente entre os seus filhos", conforme Salvetti (1995, p. 9, tradução nossa). Entre as funções desta Società estava a de privilegiar a cultura e a propaganda no exterior, visando que o aprendizado elementar dos filhos dos emigrantes, fosse um pouco adiante do "italiano que pouco conhecem e principalmente de forma dialetal". De modo que, a função das escolas italianas no exterior era a de enaltecer a educação nacional e o sentimento pátrio, utilizando-se "da língua italiana como meio de manter forte o legado entre os emigrados e a mãe pátria", de acordo com Salvetti (2002, p.48, tradução nossa).

Desta forma, o governo italiano contribuía com a instrução elementar das crianças italianas, ou filhas de italianos, que viviam fora da Itália. Com o envio de subsídios em espécie, de materiais didáticos e com a manutenção das escolas italianas all'estero. Os incentivos eram enviados a partir da Società Dante Alighieri, que visava a necessidade da criação e manutenção do ideal de italianidade. Nesse ponto, é necessário ressaltar que, a Itália havia vivenciado um processo de unificação territorial e política durante a segunda metade do século XIX. Persistindo ainda alguns resquícios culturais, sociais, políticos e até mesmo linguísticos das segmentações regionais existentes nos momentos anteriores a essa unificação.

\section{A população imigrante nas cidades paulistas.}

Muitos dos imigrantes, que em um primeiro momento fixaram-se nas fazendas de café ou nos núcleos coloniais, passaram a buscar melhores condições de trabalho. Voltando para o país de origem, ou apenas vendendo o lote adquirido no núcleo colonial e mudandose para a área urbana. Algumas das cidades paulistas apresentaram grande crescimento industrial nos anos finais do século XIX. Muitos investidores adquiriram lotes dos antigos colonos, para a criação de indústrias, que usaria a mão de obra dos moradores locais. Sendo mais viável, nesse caso, a aquisição de lotes em antigos núcleos que estivessem localizados nas proximidades de estradas de ferro ou de grandes centros. Esse foi o ocorrido nos núcleos coloniais imperiais da Glória - que atualmente integra o bairro de Vila Mariana na cidade de São Paulo, e de São Caetano; e no núcleo provincial de Ribeirão Pires, estes últimos localizados nos arredores da Capital paulista. Os mencionados núcleos foram criados com a finalidade de abastecerem os moradores da cidade paulistana com seus produtos agrícolas. Outros núcleos haviam sido instalados na mesma época, com a mesma finalidade: o de Santana, que atualmente é um bairro da cidade de São Paulo, e o de São Bernardo, que hoje em dia é um município denominado como São Bernardo do Campo.

Diversas localidades urbanas, que não contaram com núcleos coloniais com predominância de peninsulares, acabaram por se tornarem centros urbanos em função da mão de obra dos imigrantes. Algumas regiões consideravam que os peninsulares vindos da área urbana já teriam melhor desempenho nas funções que a cidade requeria. De acordo com Fausto (1991, p. 31), a questão crucial que envolveu a "inserção dos imigrantes no meio urbano" foi a sua presença maciça nesses centros e ao trabalho extremamente qualificado "a partir da pequena oficina e do comércio miúdo". 


\begin{abstract}
Embora nos falte conhecer muito da cultura e da organização social do país de origem, penso que ninguém desmentiu algumas constatações tradicionais, correlacionando habilidades prévias e oportunidades existentes no país. Qualidades originárias, como, por exemplo, as virtudes artesanais do trabalhador italiano, não podem ser pensadas em abstrato. Quaisquer que possam ter sido seus limites, a meu ver elas se destacam [...] Lembro por último que, se muitas opções de trabalho foram abertas pelas condições locais, habilidades e atividades prévias parecem ter constituído um fator importante, como é o caso de bareses dedicados ao comércio de peixe e outros comestíveis. (FAUSTO, 1991, p. 32)
\end{abstract}

No antigo núcleo colonial estadual de Piagui, na atual cidade de Guaratinguetá, a contribuição dos imigrantes ao desenvolvimento do município foi grande. De acordo com Giffoni Junior (2003) os imigrantes trouxeram novas técnicas de trabalho, que eram utilizadas nas regiões nas quais viviam, proporcionando um rápido desenvolvimento comercial.

O núcleo colonial imperial Senador Antônio Prado, que atualmente integra a cidade de Ribeirão Preto foi criado visando a fixação de mão de obra nos arredores das fazendas de café, além de abastecer os centros urbanos com gêneros de subsistência. Os lotes deste núcleo foram vendidos aos imigrantes com profissões urbanas, principalmente peninsulares, que adquiriram a maior parte das terras. Com o crescimento, a urbanização do núcleo foi inevitável, porque:

[...] havia uma multiplicidade de segmentos de serviços e manufatureiros que serviam como suporte da produção e circulação de mercadorias, como os motoristas de "carros de aluguel" e as oficinas de carroças. No ramo da construção, além da concentração de mão-de-obra especializada, decorrente da quantidade de imigrantes que já exerciam o ofício principalmente na Itália, observou-se a presença de olarias e depósitos de materiais. (MANHAS \& MANHAS, 2011, p.10)

No atual município de Salto a fábrica de tecidos arregimentava funcionários brasileiros e imigrantes, mas segundo dados de Rossi (1991) no ano de 1901 mais da metade dos operários eram estrangeiros. Como essa empresa mantinha em seus quadros profissionais, vindos da Itália, os peninsulares que deixavam o trabalho nas fazendas próximas a esta cidade buscavam emprego na fábrica de tecidos.

No núcleo colonial estadual de Nova Odessa, existiam vários grupos étnicos, muitas das mulheres desta comunidade buscavam trabalho como tecelãs na Fábrica de Tecidos Carioba, na atual cidade de Americana. Nas proximidades desta Fábrica existia uma escola mista pública noturna para menores operários, segundo dados do Annuario de Ensino de 1910.

A cidade de São Paulo agregou pessoas vindas das mais diversas localidades do estado. O crescimento da população justificou-se pelo amplo número de indivíduos que se dirigiram para o novo centro comercial e industrial. Com a expansão e a importância na produção e exportação de café, a cidade se tornou um polo de convergência aos interesses dos mais diversos.

Com o crescimento descomedido da população urbana, era necessário que os próprios estrangeiros se organizassem, na tentativa de suprirem as lacunas que o governo 
local não conseguia preencher. Essa é uma das hipóteses para a existência das inúmeras escolas privadas italianas paulistanas, nesse período.

A cidade de São Paulo, segundo Biondi (2010, p. 24) se inseriu em um contexto singular, transformou-se, "durante o século XX, na metrópole com o maior número de descendentes de italianos no mundo, caracterizando-se, no início de sua expansão, como a cidade industrial do Brasil, na qual a componente italiana era majoritária em todos os setores de trabalho."

As escolas privadas subsidiadas pelo governo italiano somente na cidade de São Paulo chegaram a atender sete mil alunos nos primeiros anos do século XX, conforme os dados constantes nos Annuarios do Ensino do Estado de São Paulo (1909, p. 45). No estado paulista, existiam 80.469 alunos nas escolas públicas estaduais (masculinas, femininas, mistas, reunidas e grupos escolares) e 13.561 nas escolas municipais.

As escolas municipais eram providas e mantidas pela prefeitura das cidades, que apresentavam condições financeiras para essa empreitada. Todos os alunos que frequentavam as escolas elementares paulistas públicas eram moradores das respectivas localidades, e certamente, muitas dessas crianças eram provenientes de outros países, ou eram filhas de estrangeiros, nascidas no Brasil. Não se pode deixar de crer, que foram vários os peninsulares que enviaram seus filhos para as escolas públicas paulistas, como foi constatado nas listas de chamada das escolas dos antigos núcleos coloniais de São Caetano e de Ribeirão Pires, entre outros, apesar da existência de escolas elementares privadas italianas.

\section{Escolas elementares privadas italianas nos centros urbanos paulistas.}

Os longos textos escritos nos relatórios dos inspetores escolares constantes nos Annuarios do Ensino apresentavam algumas das dificuldades do governo do estado em lidar com o número excessivo de escolas estrangeiras. O ponto crucial dos debates e discursos dos inspetores escolares era o da precariedade das escolas públicas de ensino primário, contribuindo sobremaneira com o crescimento das escolas privadas. A criação das escolas privadas italianas supria a defasagem de escolas elementares e ainda reforçava a difusão do idioma instituído como oficial após a unificação territorial.

A abertura de estabelecimentos de ensino particulares pelos próprios conterrâneos, nos moldes das escolas italianas, foi uma solução muito bem aceita pelos peninsulares, sendo que essas escolas visavam a alfabetização das crianças na língua pátria de seu país de origem. Existiam no estado paulista 154 escolas elementares estrangeiras, em 27 municípios, como informou o Annuario do Ensino do ano de 1909.

Mas, essas escolas representavam um risco à nação brasileira, porque formavam crianças brasileiras natas em cidadãos italianos, sendo que seus alunos frequentes eram todos italianos ou filhos de italianos. Seus professores ou diretores, também eram peninsulares, como foi ilustrado no Annuario do Ensino de 1910.

A periculosidade das escolas italianas estava no fato de que ensinavam as crianças a amar outro país, de modo que o baixo número de inspetores escolares no estado impossibilitava a efetiva fiscalização. O recurso encontrado por um dos inspetores era de que o governo do estado fizesse a doação de materiais para o ensino, como livros de História e de Geografia do Brasil, e deste modo, instituísse que essas escolas tivessem professores brasileiros para o ensino de Língua Pátria, da História e da Geografia do Brasil. Cogitou-se, deste modo, a possibilidade de o governo encerrar as atividades das escolas italianas de ensino primário, que não cumprissem com essas determinações. 
O argumento apresentado sobre o encerramento das atividades dessas escolas, não condizia com a realidade escolar de São Paulo naquele momento. O governo do estado não possuía verbas suficientes para criar novas escolas, em um número satisfatório que pudesse suprir a demanda das crianças estrangeiras. O ponto central da questão ainda permanecia o mesmo desde o início das discussões, a minguada verba pública disponível para o ensino. Portanto, os estrangeiros - tendo em vista esse quadro desolador da instrução pública, passaram a abrir escolas elementares privadas. E, na medida em que essas iniciativas foram bem recebidas pela comunidade, abriram-se escolas maiores e mais organizadas.

$\mathrm{Na}$ cidade de Campinas, como na Capital do estado, muitos moradores eram antigos trabalhadores agrícolas que saíram das fazendas de café e rumaram para a cidade em busca de novas oportunidades de trabalho. A cidade campineira foi um centro urbano que atraiu indivíduos das mais variadas etnias, contribuindo com a criação de escolas elementares públicas e privadas.

No ano de 1881 foi criado o Circolo Italiano Uniti, que mantinha em funcionamento uma escola. Como foi descrito por Cunha (2006, p. 33), a escola "preenchia uma lacuna existente na cidade referente a educação da colônia italiana". As escolas dessa associação, diferentes de outras existentes no estado, eram masculinas e femininas e aceitavam como alunos os filhos dos sócios e os órfãos nacionais e estrangeiros. Os conteúdos contavam com aulas de "Italiano, Portuguez, arithmetica e desenho linear". Apesar da flexibilidade de seu estatuto, observou-se que nas listagens com os nomes dos alunos, somente constavam crianças com sobrenomes de peninsulares. Ainda na cidade de Campinas, como descreveu Corrêa (2000), existiram as escolas da Sociedade Confederata, uma masculina e outra feminina, com todos seus alunos descendentes de peninsulares.

\section{Considerações Finais.}

As escolas de Primeiras Letras foram criadas pelo governo paulista, na maioria das localidades, com o intuito de alfabetizar a população em idade escolar. Em contraponto, o governo italiano incentivava a instituição de escolas elementares privadas, enviando subsídios para seu funcionamento. As escolas elementares públicas no estado de São Paulo eram em maior número que as privadas italianas, mas tinham em seus bancos muitos estrangeiros e filhos de estrangeiros.

Nas escolas das associações de mútuo socorro e nas privadas subsidiadas todos falavam o italiano, ou o idioma regional da localidade na qual residiam. A criação das escolas privadas foi baseada no alto número de crianças peninsulares e descendentes em idade escolar, que não frequentavam nenhuma instituição de ensino.

O processo de criação e instalação das escolas de Primeiras Letras nas localidades paulistas seguiu um padrão. Nos núcleos coloniais o governo criava uma escola mista, ou uma feminina e uma masculina, nomeava os professores e, com o passar do tempo equipava as escolas com materiais. Dentre os núcleos coloniais aqui estudados, apenas os estaduais, Jorge Tibiriçá, atual cidade de Corumbataí e Nova Odessa, apresentaram informações extremamente esparsas sobre as escolas. Como foram criados no ano de 1905, não foi possível encontrar muitos dados sobre a criação e provimentos das escolas nesses núcleos. Levanta-se a hipótese de que, pela proximidade com outras localidades, as crianças deslocavam-se desses núcleos para as escolas existentes nos arredores. Muitos foram os relatos de crianças que caminhavam várias léguas para chegarem à escola isolada mista mais próxima, ou que frequentaram a escola isolada, que existia na fazenda de café em que seus pais trabalhavam. Normalmente essa escola era fundada por iniciativa do 
proprietário da fazenda, que providenciava uma professora e alguns materiais para seu funcionamento.

Nos centros urbanos as escolas isoladas foram logo extintas, tornavam-se escolas reunidas, categoria que antecedia a instituição dos grupos escolares. As escolas privadas das associações de socorro mútuo do interior do estado expandiram-se, muitas associações tinham além de escolas, bandas de músicas e grupos de teatro, com participação das crianças.

Apesar da existência das muitas escolas elementares públicas ou privadas nas terras paulistas, não se pode afirmar que a maioria das crianças em idade escolar, estrangeiras ou filhas de estrangeiros, tenham frequentado a escola nesses anos estudados. Constatou-se, entretanto, que muitos peninsulares e filhos de peninsulares estiveram nos bancos das escolas isoladas públicas paulistas, a partir da análise das listas de chamadas.

\section{Referências}

BIONDI, Luigi. Imigração italiana e movimento operário em São Paulo: um balanço historiográfico. In: CARNEIRO, Maria Luiza T.; CROCI, Federico \& FRANZINA, Emilio. (Org.s) História do trabalho e História da imigração: trabalhadores italianos e sindicatos no Brasil (séculos XIX e XX). São Paulo: EDUSP:FAPESP, 2010, p. 23-48.

CORRÊA, Rosa L. T. Conviver e sobreviver: estratégias educativas de imigrantes italianos (1880-1920). [Tese], São Paulo: USP, 2000.

CUNHA, Maria Inês B. da.O legado das escolas dos imigrantes italianos para a história da educação brasileira. [Monografia], Campinas: UNICAMP, 2006.

DI LORENZO, Ana Lucia. Italianos em Taubaté: o núcleo colonial do Quiririm 1890/1920. [Mestrado], São Paulo: USP, 2002.

FAUSTO, Boris. Historiografia da imigração para São Paulo. São Paulo: Sumaré: FAPESP, 1991.

GIFFONI JÚNIOR, Marco A. A Imigração Italiana na Cidade de Guaratinguetá. [Monografia], Taubaté: Universidade de Taubaté, 2003.

GRANJO, Maria Helena B. Escola masculina de Ribeirão Pires (1912-1918). Curitiba, Anais do III Congresso Brasileiro de História da Educação: educação escolar em perspectiva histórica, 2004.

MANHAS, Adriana C. B. S.; MANHAS, Max P. G. Traçado urbano e funcionamento do núcleo colonial Antônio Prado em Ribeirão Preto - São Paulo em 1887. Paraty/RJ, Anais do $1^{\circ}$ Simpósio Brasileiro de Cartografia Histórica: passado presente nos velhos mapas conhecimento e poder, 2011.

MIMESSE, Eliane. A educação e os imigrantes italianos: da escola de primeiras letras ao grupo escolar. 2. ed. São Paulo: Iglu, 2010.

Revista HISTEDBR On-line, Campinas, $n^{o}$ 63, p. 259-269, jun2015 - ISSN: 1676-2584 
PISERI, Maurizio (Org.). L'alfabeto in montagna. Scuola e alfabetismo nell'area alpina traetà moderna e XIX secolo. Milano: F. Angeli, 2012.

ROSSI, Anicleide Z. O quintal da fábrica. [Dissertação], Campinas: UNICAMP, 1991.

SALVETTI, Patrizia. Le scuoleitalianeall' estero. In: BEVILACQUA, Piero; DE CLEMENTI, Andreina\& FRANZINA, Emilio. Storia dell'emigrazione italiana: arrivi. Vol. 2. Roma: Donzelli, 2002, p. 535-549.

Immagine nazionale ed emigrazione nella Società "Dante Alighieri". Roma: Bonacci, 1995.

SÃO PAULO. Annuarios do Ensino do Estado de São Paulo:publicação organisada pela Inspectoria Geral do Ensino por ordem do Governo do Estado. São Paulo: Typ. Siqueira $\&$ C., 1907 a 1910.

SILVEIRA, Marcel C. Imigração italiana em Limeira - São Paulo: terra, política e instrução escolas. [Dissertação], Campinas: UNICAMP, 2007.

1 Doutora em Educação pela PUC/SP. Pós-Doutora em História pela PUC/SP. Professora do Centro Universitário Internacional/UNINTER.

Recebido: $\quad$ março-14 abril-15 